University of Nebraska - Lincoln

DigitalCommons@University of Nebraska - Lincoln

To Improve the Academy

Professional and Organizational Development

Network in Higher Education

1998

\title{
Holistic Faculty Development: Supporting Personal, Professional, and Organizational Well-Being
}

Glenda T. Hubbard

Sally S. Atkins

Kathleen T. Brinko

Follow this and additional works at: https://digitalcommons.unl.edu/podimproveacad

Part of the Higher Education Administration Commons

Hubbard, Glenda T.; Atkins, Sally S.; and Brinko, Kathleen T., "Holistic Faculty Development: Supporting Personal, Professional, and Organizational Well-Being" (1998). To Improve the Academy. 405.

https://digitalcommons.unl.edu/podimproveacad/405

This Article is brought to you for free and open access by the Professional and Organizational Development Network in Higher Education at DigitalCommons@University of Nebraska - Lincoln. It has been accepted for inclusion in To Improve the Academy by an authorized administrator of DigitalCommons@University of Nebraska - Lincoln. 
Hubbard, G. T., Atkins, S. S., \& Brinko, K. T. (1998). Holistic faculty development: Supporting personal, professional, and organizational well-being. In M. Kaplan (Ed.), To Improve the Academy, Vol. 17, (pp. 35-50). Stillwater, OK: New Forums Press and the Professional and Organizational Development Network in Higher Education. Key Words: faculty development programs, cooperation, innovation.

\section{Holistic Faculty}

Development: Supporting

Personal, Professional, and

Organizational Well-Being

\section{Glenda T. Hubbard}

\section{Sally S. Atkins}

\section{Kathleen T. Brinko}

Appalachian State University

In recent years, higher education has begun to realize the great influence that faculty quality of life has on student learning and on overall institutional effectiveness. This article examines the interactive effect of personal, professional, and organizational well-being and describes a center that integrates four kinds of services - faculty development, employee assistance, health promotion, and organizational development - that work both separately and collaboratively. The result is a synergistic organization that is able to tackle complex institutional problems that could not be addressed by any one program alone.

In recent years the issues facing institutions of higher education have become increasingly challenging and complex. Demands for greater 
accountability, the loss of public trust, and increasing financial constraints place great pressure on academic institutions. These pressures - along with increasingly stringent requirements for promotion and tenure, decreasing mobility, and erosion of faculty autonomyoften create significant stress for faculty members.

Consider for a moment the following scenarios:

Professor $\mathrm{X}$ is 29. She has just completed her doctorate, and this is her first full-time faculty position. She is enthusiastic about entering the ranks of the faculty of her university, but she is increasingly concerned about the mixed messages she receives about research expectations in her department. Although the primary mission of her university is teaching, her colleagues tell her that in reality it is only publications that matter for promotion and tenure. She wants to get involved in research but finds that her teaching load of four large classes takes all her time. In addition, she is a single parent with a young child, and child care options are very limited in the community.

Professor $\mathrm{Y}$ is 55 . He is a tenured full professor, and for the past ten years he has served as chairperson of his department. He is a highly respected leader within the university, yet his position as chair has become less and less satisfying to him. He reports that the amount of paperwork and "administrivia" has quadrupled since he took the position, and he feels he has no time to support and mentor his faculty, the activity that he most enjoys. He is considering resigning, but he is anxious about returning to the classroom full-time because he has fallen behind in his field. He also has a heart problem; his two children are both in college; and he is dealing with an aging and infirm parent.

Department $\mathrm{Z}$ is troubled. Although faculty members are respected scholars and successful teachers, the department is deeply factionalized. Departmental meetings are politicized and rancorous. New faculty are afraid to speak, and they are pressed to "take sides" in order to survive. Two chairpersons have resigned in three years. Several faculty in the department describe the atmosphere as "toxic."

Such stories illustrate the complicated interaction of personal, professional, and organizational challenges faced by university faculty and administrators. Stories like these demonstrate that it is virtually impossible to separate personal and professional concerns from institutional issues. As Nevitt Sanford (1980) pointed out almost two decades ago, if institutions of higher education wish to improve the learning possibilities they offer to students, they must become vitally 
interested in the individual development - both personal and professional -of their faculty and in the culture of the institution.

Most traditional faculty development programs emphasize professional development, and many concentrate their efforts on instructional development. Faculty developers are discovering that this focus fails to take into account the influences of emotional and physiological factors on teaching performance. When faculty members experience difficulties in teaching-for example, poor teaching evaluations by students, peers, or supervisors - they often cite non-instructional factors as limiting their performance: "My teaching is suffering terribly because my marriage is breaking up." "I am spending all my energy trying to get my son off drugs. My job is taking a back seat." "I drink every day; I start first thing in the morning, every morning." "My chair has been so abusive that I can barely function in faculty meetings or class." "My weight problem is definitely related to my teaching evaluations; I binge when I'm depressed." "I am so afraid of having a heart attack the way my father did at my age." "The atmosphere in my department is so awful that I can't eat at work, and this plays havoc with my blood sugar."

Trying to separate instructional concerns from issues regarding health, nutrition, exercise, family, child-rearing, marriage, promotion and tenure, and institutional politics is futile. Troubled faculty are often so distracted by personal and organizational problems that they are incapable of giving attention to suggested teaching strategies. A forward-looking faculty development center must continue providing resources that enhance teaching and learning; however, instructional development activities alone are not sufficient to improve faculty performance and satisfaction.

\section{Historical Context}

Historically, support services for faculty have been scant. Recently, universities and colleges have offered more services to support faculty, but these services are often decentralized and offered in very separate arenas. For example, many institutions offer instructional support, including media services. However, faculty in many institutions find support for their physical health, if at all, in the student 
fitness center and can only access personal counseling off-campus in the local mental health facility.

Professional Development. Early faculty development efforts of the 1970 s attempted to improve institutional effectiveness by addressing the disciplinary expertise or pedagogical skills of faculty members. Subsequent approaches over the next two decades focused upon understanding the complexity of the teaching/learning process, expanding faculty awareness of new emerging information about cognition and development, and incorporating technology into the classroom. In recent years, faculty developers have expanded these traditional instructional development efforts, augmenting them with personal and organizational support in order to address issues of faculty vitality and renewal (Bland \& Schmitz, 1988; Boice, 1986; Karpiak, 1997; Sorcinelli, 1992).

Mental Health. Employee assistance services have been an established part of business and industry for many years. First designed to assist employees with chemical abuse problems, many employee assistance programs have been broadened to include any type of problem resulting in impaired job performance. While Hosokawa (1990) believes that employee assistance programs for faculty "can make a unique contribution to the enhancement of a faculty career," few campuses presently offer employee assistance programs to their faculty.

Physical Health. The interrelationship between physical well-being and work performance is well established (North, 1991). Faculty members who are exhausted, stressed, or plagued by illness are unlikely to be inspiring, innovative teachers. More than two hundred campuses have established health promotion programs (North \& Munson, 1990). Many embrace not only physical health, but also other dimensions of well-being such as social, emotional, spiritual, intellectual, and occupational wellness. Despite the overlap of purposes, few employee wellness programs operate in conjunction with faculty development programs (North, 1991).

Coordination among Programs. Steiger (1994) encourages the coordination of employee assistance and wellness programs. He believes that such coordinated programs can revolutionize the workplace, not only by cutting costs of health care and employee turnover, 
but also by redefining the concept of work. He urges businesses to integrate health and work, thereby changing attitudes to create a healthy, productive employee.

Austin, Brocato, and Rohrer (1997) discuss role-related stress of faculty members and suggest that faculty development efforts need to expand services to decrease faculty stress. They emphasize that faculty are expected to fill multiple and conflicting roles, creating a need for assistance that goes beyond traditional offerings. These new programs need to incorporate attention to the institutional mission, faculty roles and responsibilities related to the mission, and challenges faculty face at various stages of their lives.

Schuster and Wheeler (1990) point to the need for an "enhanced faculty development concept which integrates personal, professional, and organizational aspects of development." Such an approach should include not only traditional aspects of faculty development, but also concern for faculty wellness and institutional quality of life, as well as opportunities for personal growth and career renewal (Hagaseth \& Atkins, 1988; North, 1991).

The question then becomes how to address the larger issue of institutional, professional, and personal change as a whole, interrelated and interacting, multifaceted system. In today's society, experts in a variety of fields are rejecting divisions such as "body/mind," "physical/mental/spiritual," "professional/personal" and are moving toward more holistic definitions of human functioning. A holistic approach to providing support to faculty would include an integrated approach to individual and organizational needs, including services to promote physical, mental, emotional, and professional health.

\section{Reorganizing Toward a Holistic Approach to Faculty Development}

Appalachian Sate University-a mid-size, state-supported institution-established the Center for Instructional Development in 1975, the Employee Assistance Service in 1975, and the Health Promotion program in 1980 as separate entities, located in different parts of the campus and reporting to different units in the adminstrative structure. Over the next fifteen years, Appalachian's faculty development spe- 
cialists observed that many faculty were experiencing a variety of personal, work-related, and family problems that were detrimental to effective teaching. During this period the university was also involved in ongoing studies of institutional climate and faculty/staff quality of life (Atkins \& Hageseth, 1991; Hagaseth \& Atkins, 1988; Hagaseth \& Atkins, 1989.) In 1993, after extensive analysis of faculty needs and of available personnel and other resources, the Provost re-organized the support services for faculty, administratively aligning and physically locating the faculty development program (now called Faculty and Academic Development) with Health Promotion and the Employee Assistance Service. This new entity became the Hubbard Center for Faculty and Staff Support. Recently the Center created a fourth component, Organizational Development, in order to focus directly upon issues of organizational well-being and institutional change.

\section{Faculty and Academic Development}

Faculty and Academic Development (FAD) enhances faculty quality of life through professional development opportunities. Activities focus on enriching and deepening the performance and satisfaction of faculty through a variety of programs and services: workshops about teaching, learning, academic career development, and trends in higher education; mini-grants to strengthen teaching and learning; funding for faculty to learn new disciplinary information or teaching skills; special interest groups and teaching circles on a wide variety of topics; a library of resources on teaching, learning, and higher education; instructional consultation; and special support for new faculty, including orientation, mentoring, and a facilitated book group.

\section{Employee Assistance Service}

The Employee Assistance Service (EAS) is a confidential counseling service established to ameliorate personal problems, especially when they might interfere with work performance. Thus EAS provides assessment, referral, and counseling for faculty and staff who are experiencing difficulty with issues such as depression, stress, sub- 
stance abuse, traumatic residue of childhood sexual abuse, eating disorders, marital problems, parenting, conflicts between employees and supervisors, problems of adjustment for new faculty, problems with efforts to complete dissertations, problems resulting from divorce or bereavement, and a variety of other issues. A recent addition to these services is mediation, a process of structured sessions to help individual employees to resolve interpersonal conflicts.

\section{Health Promotion}

The Health Promotion (HP) program focuses on the connection between health habits-lifestyle and choices made-and the level of health enjoyed by faculty and staff. HP programs and services include workshops on nutrition and health issues, smoking cessation groups, weight-loss and exercise programs, health screenings (e.g., cholesterol, diabetes, and skin, breast, and prostate cancer), CPR and first-aid classes, massage therapy, and individual consultation on nutritional and health concerns.

\section{Organizational Development}

While not a "program" in the same sense as the above three programs, Organizational Development (OD) has become an important component of the Center's functioning. OD focuses on issues affecting the personal and professional vitality of faculty and staff within the organizational culture in which they work. The Director of OD works with a committee of selected and volunteer faculty, staff, and administrators, representing broad areas within the university, including the directors of each of the other three programs within the Hubbard Center.

The OD Committee functions as a "think tank" with regard to identifying issues that impact the quality of life of all members of the university. The first activity undertaken by the OD Committee was a year-long collective study of Peter Senge's (1990) The Fifth Discipline to learn about systems thinking and to provide a common language and structure within which to consider organizational issues. Activities sponsored by the Committee include chairperson training and support, departmental interventions, an administrative internship pro- 
gram, leadership retreats, and research studies of climate and quality of life of faculty and staff.

\section{Implementing a Holistic Approach: Collaboration and Synergy Among Programs}

In 1993 as we re-organized into the new entity, we wrote the mission statement of the Hubbard Center to reflect the close relationship among the programs:

Recognizing that each individual is valuable and makes unique contributions to the University, the Hubbard Center has as its primary goal to enhance the quality of life of all faculty and staff. Program services focus on physical, emotional, and work-related needs in order to enhance the work satisfaction and personal life of faculty and staff... It is the belief of the Center that when individuals' lives are influenced in positive ways, the institutional and organizational quality of the University is also enhanced. (Hubbard Center Twenty-Second Annual Report, 1997, p. 29).

As we had hoped at the time of the reorganization, we have formed a very collaborative relationship among the programs. We share many of the same philosophical underpinnings (such as the primacy of confidentiality) and many of the same challenges (such as how to reach populations most in need of our services). Many referrals are made from one program to another; in fact, many faculty are being served by two or three programs. For example, it is not uncommon for a faculty member with a marital problem to seek help from EAS. Then during the course of therapy, we might refer her to HP for cholesterol testing, dietary changes, and weight control issues, after which she might seek help from a faculty development consultant on teaching strategies. Similarly, we see a number of faculty who seek instructional advice, for example, on how to incorporate active learning into their courses. In the conversation, we learn that the same individual is experiencing interpersonal problems with senior colleagues and is very concerned about achieving promotion and tenure, and we refer him to EAS, who then refers him to HP for stress and blood pressure testing. Faculty who have utilized services in these ways report 
considerable improvements in teaching skills, in self esteem, and in self confidence with regard to both family and teaching.

\section{Collaboration Among Programs}

Beyond inter-program referrals, the four programs collaborate to create ways to plan and deliver programs and services more effectively. For example, the Directors of the Employee Assistance Service and Health Promotion meet at intervals to discuss faculty and staff needs, and the Director of HP invites the Director of EAS to participate in brainstorming sessions with the HP Advisory Council. This combination allows both organizations to receive maximum feedback from faculty without having to organize an additional advisory board. Further, EAS and HP staff engage in both formal and informal collaboration, consulting about mental and physical health issues involved in referrals and in making presentations to faculty and staff. For example, the Director of EAS sought advice from HP's dietition in writing an article for parents, and the two did a joint presentation on eating disorders at a colloquium for faculty, staff, and students.

Similarly, the staff of Faculty and Academic Development and Employee Assistance Services collaborate to produce programming that crosses the boundaries of traditional faculty development. For example, FAD and EAS jointly planned and sponsored a special interest group for mature faculty who read the book, In Our Fifties: Men and Women Reinventing Their Lives (Bergquist, Greenberg, and Klaum, 1993). While FAD supplied the logistical support and books for the participants, the Director of EAS - with her counseling expertise-conducted the group that discussed the psychological changes that one undergoes in the fifth decade of life. Additionally, each fall EAS assists FAD with the Welcome and Orientation for New Faculty. While FAD implements the program to introduce new faculty to the university, EAS conducts a parallel program for spouses and guests of new faculty, to help them adjust to living and finding employment in a rural community.

It is likely that such collaboration will continue and that programs utilizing personnel from all four programs will increase their planning of joint services. 


\section{Synergy Among Programs}

Beyond inter-program referrals and collaboration, activities related to organizational development and change have produced a synergy among the programs of the Hubbard Center. Because we bring different knowledge and perspectives, we find that we, as a team, are able to tackle complex institutional problems that could not be addressed by any one of our programs alone.

Quality of Life Studies. At the request of the Provost, the Center began a study of faculty quality of life, a follow-up of a similar study done at this university ten years earlier (Hagaseth \& Atkins, 1988). Under the leadership of the Director of Organizational Development, the OD Committee provided suggestions in the development of the research protocol and methodology. The Directors of the Hubbard Center, OD, EAS, and FAD, and a teaching faculty member from our higher education program constituted the research team. The researchers conducted 90-minute structured interviews with a ten percent stratified random sample of 48 full-time, tenure-track faculty members. Currently the research team is concluding the data analysis, and findings will be shared within the institution and within the profession. Plans for future related studies of minority faculty, administrative faculty, and staff personnel are underway.

Wildacres Retreats. Another effort undertaken by all four programs was leadership development. With the assistance of the Organizational Development Committee, the Directors of the Hubbard Center, OD, FAD, EAS, and HP organized and conducted two University leadership retreats. The first retreat, Wildacres I, focused on faculty and administrative leaders; the second retreat, Wildacres II, focused on staff and administrative leaders. Participants for each retreat were selected based on our spider web model. In this model, the organization is envisioned not as a hierarchial arrangement of units, but as interconnecting webs of people engaged in shared work and common purposes. The premise of this model is that changes in organizational culture happen, not from the top down, but from the core outward through the human connections within the system.

During the three and one-half day retreats, participants worked collectively to apply Peter Senge's (1990) five disciplines of the 
learning organization to current issues facing the University. The retreats were well-received, and a number of follow-up activities have continued: a listserv to provide continuous, ongoing conversation on topics generated at the retreats; workshops and retreats in local work settings, based on the content of Wildacres; a study group of shared readings and discussions; and individual projects of self development in areas related to Wildacres learnings.

Departmental Interventions. A third synergistic effort to emerge from the linking of the four programs is that of jointly planned and conducted departmental interventions. Some requests for interventions arise from a developmental need of the unit. For example, a department chair approached the Director of Faculty and Academic Development with a problem: members of his department were protective of their programs, which interfered with collective efforts to decide which programs to strengthen and which to eliminate. The Director of FAD teamed together with the Director of the EAS and together they helped the department to plan and implement a series of retreats on strategic planning, which took decision making from the individual to the curricular/program level.

Other requests for interventions arise from organizational crises. For example, a faculty member came to the Director of Faculty and Academic Development seeking help with a departmental conflict concerning the removal of the chairperson. First, she wanted help personally. Because of her neutrality, she was feeling assaulted by colleagues in both factions who were ardently trying to persuade her to their position and was having difficulty sleeping. Second, she wanted help for the department to help resolve the conflict over the chair. The Director of FAD called on the Director of EAS to provide the faculty member with personal counseling in setting boundaries and then to team up for a departmental mediation. Upon securing the assurance that a majority of the departmental faculty would participate, the Directors jointly facilitated two dialogues, the first with the chair absent, and the second with the chair present to provide him with feedback.

This collaborative approach to departmental intervention is effective because each of the two directors brings different skills to the interaction, and each type of skill contributes to a balanced, comple- 
mentary approach to problem solving. The FAD director contributes an extensive knowledge of faculty development needs and processes, while the EAS director contributes process skills learned from many years of group and individual counseling.

\section{Unexpected Outcomes of Holistic Faculty Development}

Although our ultimate goal is to enhance the professional performance of faculty, we consider faculty, first of all, human beings with myriad personal and professional needs functioning within a complex community. Experiences such as the Quality of Life study, Wildacres retreats, and the departmental interventions deepen our understanding of the impact of considering personal and professional well-being within an organizational system.

An unexpected outcome of approaching faculty development in this holistic manner is the synergy that we experience together as a staff. We find that as we plan together, collaborate together, and refer clients from one to another of our programs, we are increasing the quality of our relationships with one another in the Center. This results in more meaningful communication, increasing respect, and caring for one another. The effect of our work together is that we engage in less trivial talk and move quickly to deeper modes that are not burdened by defensiveness and competition so often observed in organizational structures.

Another unexpected outcome is our learning that the process of working together intensely on a challenging project gives us a chance to learn much about ourselves as a working/learning group. Accustomed to working independently, we have learned that each of our disciplines utilizes a specific language and approach to problem solving, leading us to different interpretations. But varied perspectives and different types of language can serve to elucidate as well. For example, the Director of the Hubbard Center, a biologist, uses concrete scientific language and examples which serve to clarify the more abstract vocabulary and ideas of the Director of FAD and the faculty members who have backgrounds in higher education. In turn, the Directors of EAS and OD, who have counseling backgrounds, are 
often more sensitive to the impact of emotional tone and subtle nuances of language. We have learned that the more different perspectives we consider, the richer and fuller each collaboration becomes.

These learnings have far-reaching benefits in our work individually and collectively at the Center. Through our collaboration, each of us has learned a lesson which cannot be unlearned. We no longer approach a faculty member from a single disciplinary perspective, nor consider an intervention solely of instructional strategies, marriage counseling, weight-loss techniques, or departmental retreats. Rather, we engage with the person in a dialogue enriched by different disciplines and by systems thinking, reflecting a deep appreciation for the complexities of each person's life.

\section{References}

Atkins, S. S., \& Hagaseth, J. (1991). The academic chairperson: Leading faculty is like herding cats. Journal of Staff, Program, \& Organization Development, 9, 29-35.

Austin, A. A., Brocato, J. J., \& Rohrer, J. D. (1997). Institutional missions, multiple faculty roles: Implications for faculty development. To Improve the Academy, 16, 3-20.

Bergquist, W. H., Greenberg, E. M., \& Klaum, G. A. (1993). In our fifties: Men and women reinventing their lives. San Francisco: Jossey-Bass.

Bland, C., \& Schmitz, C. C. (1988). Faculty vitality on review. Journal of Higher Education, 59, 90-224.

Boice, R. (1986). Faculty development via field programs for middle-aged, disillusioned faculty. Research in Higher Education, 25, 115-135.

Hageseth, J. A., \& Atkins, S. S. (1988). Assessing faculty quality of life. To Improve the Academy, 7, 109-120.

Hageseth, J. A., \& Atkins, S. S. (1989). Building university community: Where's the staff? Journal of Staff, Program, and Organization Development, 7, 173-180.

Hosokawa, E. P. (1990). Adapting employee assistance programs for academic settings. In J. H. Schuster, D. W. Wheeler, \& Associates (Eds.), Enhancing faculty careers (pp. 123-138). San Francisco: Jossey-Bass.

Hubbard Center Twenty-Second Annual Report. (1997). Appalachian State University.

Karpiak, I. E. (1997). University professors at mid-life: Being a part of...but feeling apart. To Improve the Academy, 16, 21-40.

North, J. (1991). Faculty vitality: 1990 and beyond. To Improve the Academy, 10, 9-18.

North, J., \& Munson, J. (1990). Promoting faculty health and wellness. In J. H. Schuster \& D. W. Wheeler (Eds.), Enhancing faculty careers: Strategies for development and renewal (pp. 106-122). San Francisco: Jossey Bass.

Sanford, N. (1980). Learning after college. Orinda, CA: Montaigne. 
Schuster, J. H., \& Wheeler, D. W. (Eds.). (1990). Enhancing faculty careers: Strategies for development and renewal. San Francisco: Jossey-Bass.

Senge, P. M. (1990). The fifth discipline: The art \& practice of the learning organization. New York: Doubleday.

Sorcinelli, M. D. (1992). New and junior faculty stress: Research and responses. In M. D. Sorcinelli \& A. E. Austin (Eds.), Developing new and junior faculty (pp. 27-37). New Directions for Teaching and Learning, No. 50. San Francisco: Jossey-Bass.

Steiger, H. (1994). Dual commitment: Coordinating EAP and wellness. Employee Assistance, 6, 29-34.

Contacts:

Glenda T. Hubbard

Employee Assistance Service

Hubbard Center for Faculty and Staff Support

P. O. Box 32074

Appalachian State University

Boone, NC 28608-2074

(828) 262-4951

(828) 262-6159 FAX

hubbardgt@appstate.edu

Sally S. Atkins

Orgainzational Development

Hubbard Center for Faculty and Staff Support

P. O. Box 32074

Appalachian State University

Boone, NC 28608-2074

(828) 262-3043

(828) 262-6159 FAX

atkinsss@appstate.edu

Kathleen T. Brinko

Faculty and Academic Development

Hubbard Center for Faculty and Staff Support

P. O. Box 32074

Appalachian State University

Boone, NC 28608-2074

(828) 262-6152

(828) 262-6159 FAX

brinkokt@appstate.edu

Glenda T. Hubbard is Director of the Employee Assistance Service and Professor of Human Development and Psychological Counseling at Appalachian State University. Her experience as a counselor and a counselor educator led to her 
continuing interest in the interaction of mental, physical, emotional, and spiritual factors in quality of life of faculty, students, and staff.

Sally S. Atkins is Director of Organizational Development at the Hubbard Center and Professor of Human Development and Psychological Counseling at Appalachian State University. Her teaching and research interests include organizational change and quality of life in higher education, cross cultural counseling, expressive arts therapy, and consciousness and healing.

Kathleen T. Brinko is Director of Faculty and Academic Development and adjunct Associate Professor in the Department of Human Development and Psychological Counseling at Appalachian State University. Her research and programmatic interests include instructional consultation, teaching circles, program evaluation, faculty quality of life, and organizational development. 